\title{
Effect of Adhesive Joint on the Performance of Shoe Brake
}

\author{
P.P. Hujare ${ }^{t^{*}}$ and Rashmi Nemade ${ }^{\ddagger}$ \\ †Mechanical Engineering, Savitribai Phule University, Sinhgad Academy of Engineering, Pune, Maharashtra, India. \\ ¥Mechanical Engineering, Savitribai Phule University, Rajarshi Shahu college of Engineering, Pune, Maharashtra, India
}

Accepted 22 Dec 2016, Available online 27 Dec 2016, Vol.6, No.6 (Dec 2016)

\begin{abstract}
This paper presents the performance of the adhesive joint shear strength for a braking system. In order to understand adhesive joint shear strength, adhesive with different area of contact are tested. In experimental testing Universal Testing Machine is used to determine shear stress induced in adhesive layer applied between brake pad and brake shoe. Comparative study for single layer and multilayer adhesive is presented while evaluating at the most suitable variant of the brake shoe with respect to the area of contact of the adhesive layer and the geometry manifested by the pattern of the adhesive layer applied.
\end{abstract}

Keywords: Adhesives, adhesion, Brake shoe, Multilayer, Shear stress in joint.

\section{Introduction}

Adhesion is concerned whenever solids are brought into contact, for instance, in coatings, paints, varnishes, multi-layer sandwiches, polymer blends, filled polymers, adhesive joints, and composite materials. To make adhesion possible, it is necessary to generate intrinsic adhesion forces across the interface. Because the final performance or use properties of these multi component materials depend significantly on the quality of the interface that is formed between the solids, it is understandable that a better knowledge of adhesion phenomena is required for practical applications.

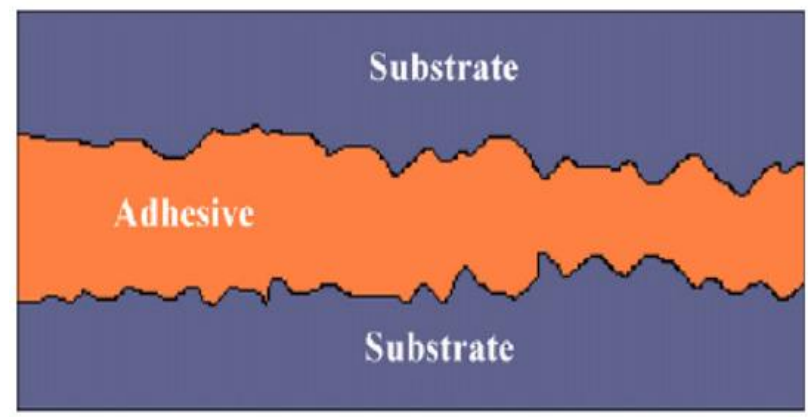

Fig. 1 Adhesive phenomenon

\subsection{Theory of Adhesives}

- The adhesives materials allow joint substrates with different geometries, sizes and composition.
- The use of adhesives eliminates the corrosion associated with dissimilar metals joining with different galvanic potential, such as the joining of steel with aluminum

- The use of adhesive as bonding material does not produce any deformation in the materials or substrates, eliminating metal grinding processes (grinding and putty), reducing the manufacturing cost and improving the aesthetics of the product.

- Do not produce any mechanical aggression to the substrate, avoiding any damage to the structure of the material.

- Great flexibility in the product design as well as an improvement in its aesthetics.

\subsection{Significance of Adhesive Joint}

\subsubsection{Literature Review}

The surface characteristics and the differences in the wear modes of the brake pads were given. These observations allowed concluding that high sliding and abrasion wear deformed the disk pad surfaces leading to form third body layers, friction layers and friction films that determined the friction behaviour of the automotive brakes (J. R. Laguna-Camacho et al, 2015) The effect of adherend's rigidity on the shear strength of single lap adhesive joints paper compares the tensile shear strength of single-lap joints with different adherends. Three materials were combined in the single lap joints: a carbon/epoxy laminated composite, a high elastic limit steel and the 6082-T6 aluminum alloy. The shear strength of joints was influenced by the adherend stiffness and the highest shear strengths 
were obtained using high stiffness adherend materials. (P. N. B. Reis et.al. 2011). It is reported that the effect of grooves on the strength of adhesively bonded joints. The objective of this work was to study the influence of the macroscopic state of the substrate surface on the strength of adhesive joints. For that, several patterns were made on the surface of aluminum substrates. The patterns were tested in two different ways, cleaned with acetone or chemically etched (Lucas F.M. da Silva et. al. 2010).

\subsubsection{Objective}

The Objective of the work under study is to find the best configuration of the area of contact for the adhesive to affect minimum permissible shear strength of the joint.

\section{Mathematical Analysis}

\subsection{Specifications of brake shoe}

The specification of brake shoe under study is as given in Table 2.1

Table 1 Specifications of brake shoe

\begin{tabular}{|c|c|}
\hline Mass of the Vehicle & $\begin{array}{c}150 \mathrm{~kg}+100 \mathrm{~kg} \\
\text { (bike + passenger) }\end{array}$ \\
\hline Maximum speed & $60 \mathrm{kmph}$ \\
\hline $\begin{array}{c}\text { Radius of the disc (where brake } \\
\text { pad is applied) }\end{array}$ & $99.8 \mathrm{~mm}$ \\
\hline Width of brake shoe & $25 \mathrm{~mm}$ \\
\hline Developed length of brake shoe & $182.38 \mathrm{~mm}$ \\
\hline Thickness of brake shoe (pad) & $4 \mathrm{~mm}$ \\
\hline
\end{tabular}

The study over the subject coatings, paints, varnishes, multilayer sandwiches, polymer blends, filled polymers, adhesive joints, and composite materials is important nowadays. To make adhesion possible, it is necessary to generate intrinsic adhesion forces across the interface. Because the final performance or use properties of these multi component materials depend significantly on the quality of the interface that is formed between the solids, it is understandable that a better knowledge of adhesion phenomena is required for practical applications. Pressures on costs and vehicle weight (meeting Corporate Average Fuel Economy (CAFE) regulations), while meeting safety goals, and further accentuate the challenge, driving the industry towards new, less costly materials and processes. The trend towards recycling the entire vehicle, already relatively strong in Europe, has recently begun to affect material and fastening choices in auto interiors in Asia. Thus, new materials and processes are continuously under development. Many of these require changes in fastening or in companion construction materials, such as adhesives done in the past have offered formulae derived by the researchers in the respective field. Application of the relevant mathematical rule to the problem at hand can lend a credible solution for finding the best alternative. Typically, the formulae in the field of Applied Mechanics or Structures can be helpful for finding a numerical value for specifying the quantum of the unit or direction for the solution [M. Y. Tsai, 1998 and Clack \& Gregor, 1993)

For a single lap joint, the maximum adhesive shear stress, $\tau_{0}$, max, can be calculated using the following equations.

$\tau_{0 \max }=\frac{\sigma}{g}(1+3 k) \sqrt{\frac{8 G a t}{E t a}}$

where,

$\begin{aligned} \sigma & =\frac{p}{t} \\ c & =\frac{L}{2}\end{aligned}$

$k=\frac{\cosh \left(u_{2} c\right) \sinh \left(u_{1} L\right)}{\sinh \left(u_{1} L\right) \cosh \left(u_{2} c\right)+\sqrt[2]{2} \cosh \left(u_{1} L\right) \sinh \left(u_{2} c\right)}$

$u_{1}=\sqrt[2]{2} u$

$u_{2}=\frac{3 \sigma\left(1-\gamma^{2}\right)}{2 E t^{2}}$

Where,

$$
\begin{aligned}
& P=\text { Load per unit width } \\
& L=\text { Length of overlap (bond length) } \\
& t=\text { Adherend thickness } \\
& E=\text { Adherend modulus } \\
& G_{a}=\text { Adhesive shear modulus } \\
& t_{a}=\text { Adhesive layer thickness } \\
& E_{a}=\text { Adhesive tensile modulus } \\
& \gamma=\text { Adherend Poisson's ratio }
\end{aligned}
$$

Now, the maximum shear stress of adhesive joint for different thickness of adhesives can be determined by using the above equation.

\section{Experimental Analysis}

\subsection{Experimental Set Up and Test Sample}

The experimental analysis is used to obtain shear stress induced in adhesive with different area of contact. The Universal Testing Machine is used for this test. The thickness of adhesive used in both brake shoes under study is $1 \mathrm{~mm}$. For experimental investigation, the brake shoe is fixed on a machine bed in a fixture with the help of clamps, as shown in Fig 2.The vertical force is applied on the brake shoe once it is placed on working surface.

Fig. 3 shows Brake shoe with fixture. The clips are used to hold the brake show in proper position during test. 


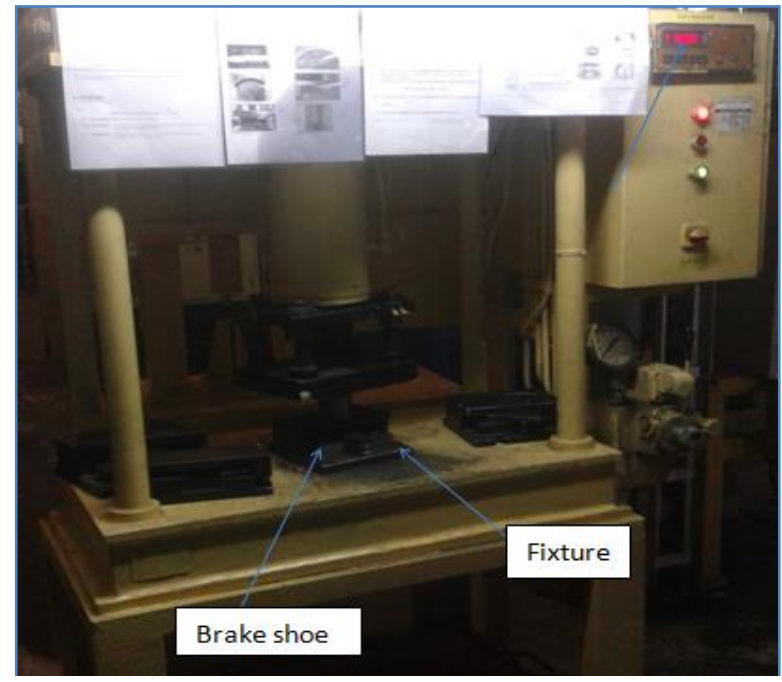

Fig. 2 Universal Testing Machine

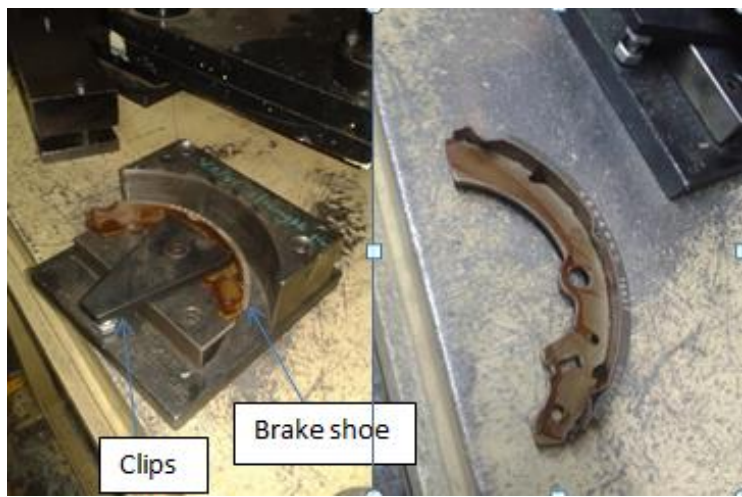

Fig. 3 Brake shoe with Fixture

Shear stress test is conducted on two types of brake shoe

1) Simple layer adhesive

2) Multi-layer adhesive

Out of above two types of adhesive of brake shoes, single layer adhesive is used conventionally. The multi layer adhesive is an adhesive applied in the form of strips more than two. Fig. 4 shows the multi-layer adhesive under study consist of four strips applied equidistantly.

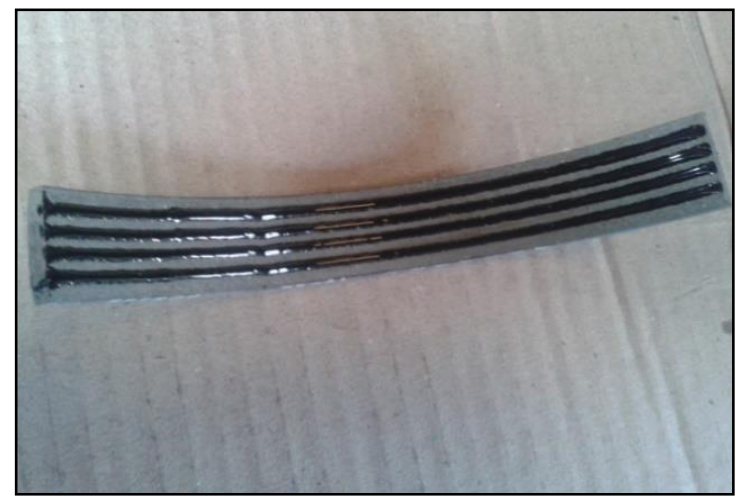

Fig. 4 Multi-layer adhesive pad
Fig. 5 shows Brake shoe with single layer Adhesive joint having 95\% adhesion after test. Fig. 6 shows brake shoe with multi-layer adhesive joint which has also $95 \%$ adhesion. The Adhesion of both Brake shoes is same; the only shear stresses are varied.

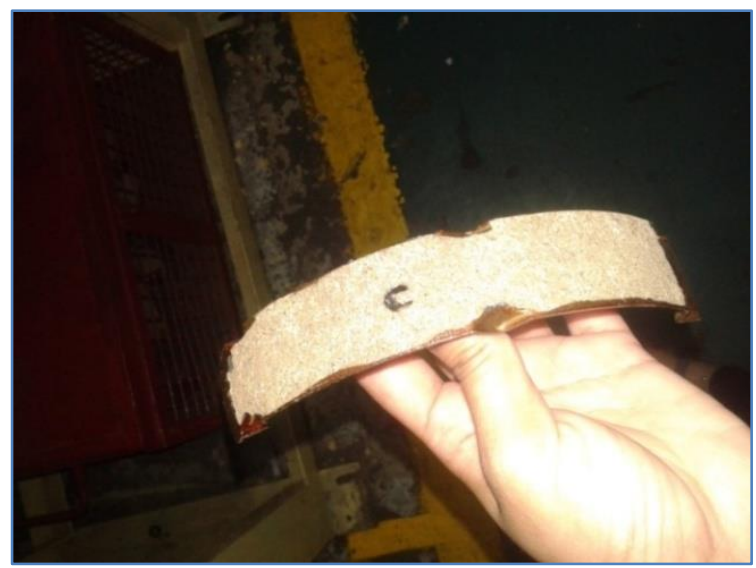

Fig. 5 Brake shoe with single layer Adhesive after failure

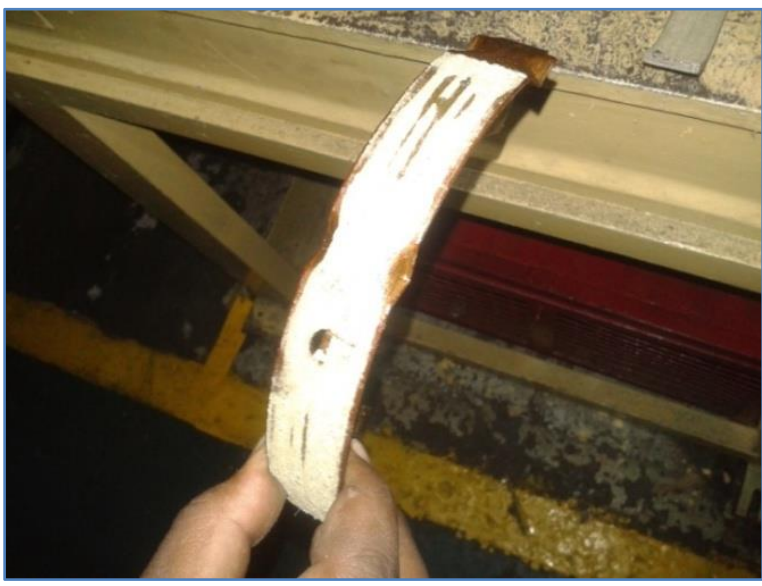

Fig. 6 Brake shoe with Multi Layer Adhesive after failure

\section{Experimental Results}

The result obtained by experimental analysis is as shown in Table 2 ,

Table 2 Experimental Results

\begin{tabular}{|c|c|c|c|}
\hline \multicolumn{2}{|c|}{ Single layer adhesive } & \multicolumn{2}{c|}{ Multi layer adhesive } \\
\hline $\begin{array}{c}\text { Shear Stress } \\
\text { (Mpa) }\end{array}$ & Adhesion & $\begin{array}{c}\text { Shear Stress } \\
\text { (Mpa) }\end{array}$ & Adhesion \\
\hline 4.86 & $95 \%$ & 4.16 & $95 \%$ \\
\hline
\end{tabular}

4. Numerical Analysis

5.

6. One of the main features of the work is the search for simplicity and robustness in all steps of the modeling, in order to match the present method with industrial practices and constraints. For analyzing the effects of the variation in the values of the design parameters 
influencing the response parameter numerical analysis is used. The CAE modelling of brake shoe under study is completed in CATIA and HYPERMESH software. The thickness of adhesive used in brake shoe under study is $1 \mathrm{~mm}$. The FEA analysis of above CAE model is performed in NASTRAN solver.

The material properties of the brake shoe parts are as shown in Table 3

Table 3 Material Properties

\begin{tabular}{|c|c|c|c|}
\hline Sr.No. & Material & $\begin{array}{c}\text { Young's } \\
\text { Modulus (Mpa) }\end{array}$ & $\begin{array}{c}\text { Poisson's } \\
\text { ration }\end{array}$ \\
\hline 1 & Adhesive & 2583 & 0.4 \\
\hline 2 & Mild steel & 210000 & 0.29 \\
\hline
\end{tabular}

\subsection{Methodology of Numerical Analysis}

- For numerical analysis, the brake shoe model consists of adhesive which is sandwich between abrasive layer and brake shoe mild steel plate.

- It is a finite element modeler used to perform a variety of $\mathrm{CAD}$ and CAE tasks including modeling, meshing and post processing for FEM solver NASTRAN. In HYPERMESH software powerful and flexible meshing is available, with capabilities that range from fully automatic solid meshing to detailed node and element editing. Loads and boundary conditions associated with design geometry can be assigned with help of HYPERMESH software.

- As shown in fig.4.1, CATIA software has been used to prepare CAD model of the brake shoe with single layer and multilayer adhesive.

- As shown in Fig. 7, the HYPERMESH software has been used to create mesh model, assign material property, load and boundary conditions. The $2 \mathrm{~mm}$ element size is used for meshing. The solid tetra elements are used for adhesive.

- The resulting visualization HYPERVIEW tool enables identification of shear stress of single layer and multilayer adhesive.

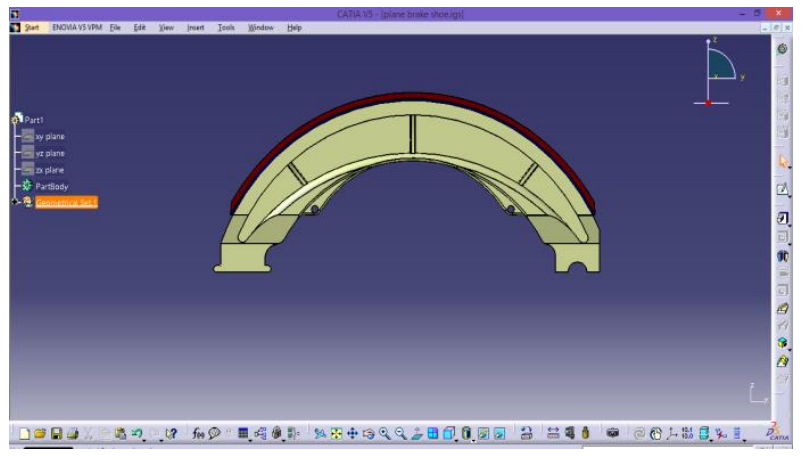

Fig. 7 Model of Brake Shoe

\subsection{Load and Boundary Conditions}

Torque is applied at the centre of the wheel and upper surface of abrasive is constrained to simulate the shear is as shown in Fig 8.

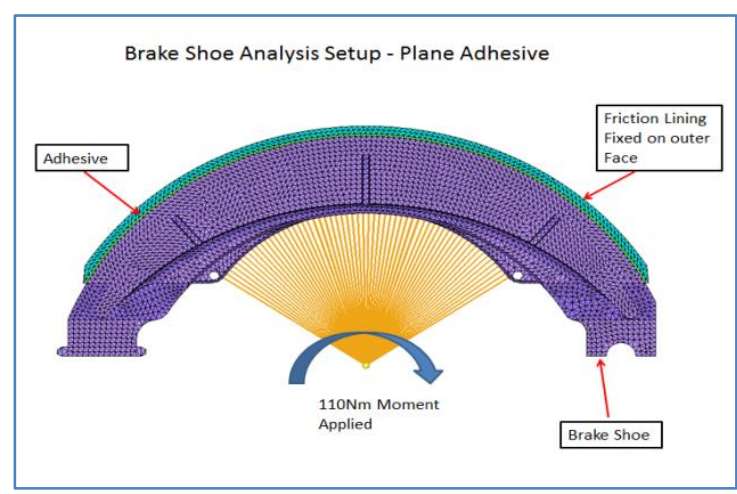

Fig. 8 Details of Brake Shoe

By using Numerical analysis shear stress contour plot of adhesive for single layer adhesive joint are observed as shown in Fig. 9. The maximum shear stress obtained is $5.20 \mathrm{Mpa}$.

\section{Variant No. 1 (Plain Layer Adhesive)}

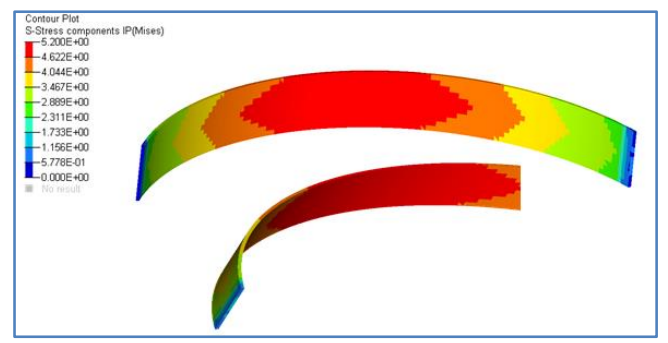

Fig. 9 Shear Stress contour plot of Single Layer Adhesive

As shown in Fig. 10, by using Numerical analysis, shear stress contour plot of multi layer adhesive joint are obtained. The maximum shear stress obtained is 4.13 $\mathrm{MPa}$.

\section{Variant No. 2 (Multi Layer Adhesive)}

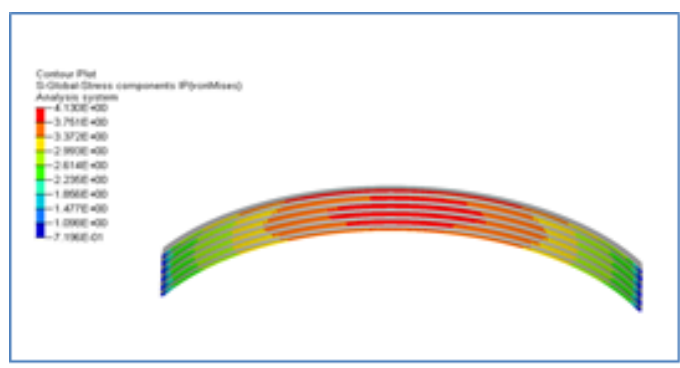

Fig. 10 Shear Stress contour plot of multi Layer Adhesive 


\subsection{Numerical Analysis Result}

The result obtained by numerical analysis is as shown in Table 4.2

Table 4 Numerical Results

\begin{tabular}{|c|c|c|c|}
\hline \multicolumn{2}{|c|}{ Single layer adhesive } & \multicolumn{2}{c|}{ Multi layer adhesive } \\
\hline $\begin{array}{c}\text { Shear Stress } \\
\text { (Mpa) }\end{array}$ & Adhesion & $\begin{array}{c}\text { Shear Stress } \\
\text { (Mpa) }\end{array}$ & Adhesion \\
\hline 5.20 & $95 \%$ & 4.13 & $95 \%$ \\
\hline
\end{tabular}

\section{Conclusions}

The experimental results show good agreement with the numerical results. The small deviation between the experimental results and the numerical results may be attributed to the bonding effect between the brake shoe and abrasive layer. The shear stress of single layer adhesive obtained by experimental analysis is 4.86 $\mathrm{MPa}$ and by numerical analysis is $5.20 \mathrm{MPa}$.The shear stress of Multi layer adhesive obtained by experimental analysis is $4.16 \mathrm{MPa}$ and by numerical analysis is 4.13 MPa. It is observed that, the $95 \%$ adhesion with single layer and multi layer brake shoe is good. It is found that the shear stress obtained in single layer adhesive is less as compare to multi layer adhesive. It is recommended that shear stress in adhesive should be less with good adhesion.

\section{Acknowledgement}

We would like to thanks Foundation Brake Mfg. Ltd., Jalgaon for their support, and encouragement.

\section{References}

Laguna-Camacho J. R., Juárez-Morales G., Calderón-Ramón C., Velázquez-Martínez V., Hernández-Romero I., Méndez-Méndez J.V., Vite-Torres M., (2015), A study of the wear mechanisms of disk and shoe brake pads, Engineering Failure Analysis 56 348-359

Reis P.N.B., Ferreira J.A.M., Antunes F., (2011), Effect of adherend's rigidity on the shear strength of single lap adhesive joints, International Journal of Adhesion \& Adhesives.

Lucas F.M. da Silva, N.M.A.J. Ferreira, V.Richter-

Trummer , E.A.S. Marques (2010) Effect ofgrooves on the strength of adhesively bonded joints, International Journal of Adhesion \& Adhesives

Rade Prashant S., Deshmukh Dheeraj S., Kulkarni Swapnil S., (2014), Investigation of Adhesive Joint Shear Strength For A Braking System, International Journal of Advanced Engineering Research and Studies

M. Y. Tsai, (1998), Improved Theoretical Solutions for Adhesive Lap Joints, International Journal of Solids Structures, 35(12), pp. 1163-1185,

Clack J D, Mc Gregor IJ. (1993), Ultimate tensile stress over a zone: a new failure criterion for adhesive joints. J. Adhes.

Bhusal K.H., Nimbalkar, S.R. Belkar S. B., Kulkarni Swapnil, (2014), Performing Finite Element Analysis For Adhesive Joint For Brake Shoe of An Automotive System While Evaluating Its Design, International Journal of Advanced Engineering Research and Studies, pp. $43-45$ 